\title{
Dimebon Does Not Ameliorate Pathological Changes Caused by Expression of Truncated (1-120) Human Alpha-Synuclein in Dopaminergic Neurons of Transgenic Mice
}

\author{
Tatyana A. Shelkovnikova ${ }^{a, c}$ Alexey A. Ustyugov ${ }^{a}$ Steven Millership ${ }^{c}$ \\ Owen Peters $^{c}$ Oleg Anichtchik ${ }^{b}$ Maria Grazia Spillantini ${ }^{b}$ Vladimir L. Buchman ${ }^{c}$ \\ Sergey O. Bachurin ${ }^{a}$ Natalia N. Ninkina ${ }^{a, c}$ \\ a Institute of Physiologically Active Compounds RAS, Chernogolovka, Russian Federation; \\ ${ }^{b}$ Centre for Brain Repair and Department of Clinical Neurosciences, University of Cambridge, Cambridge, and \\ 'School of Biosciences, Cardiff University, Cardiff, UK
}

\section{Key Words}

Dimebon • Transgenic mouse model $\cdot \alpha$-Synuclein •

Parkinson's disease $\cdot$ Preclinical drug testing

\begin{abstract}
Background: Recent clinical studies have demonstrated that dimebon, a drug originally designed and used as a nonselective antihistamine, ameliorates symptoms and delays progress of mild to moderate forms of Alzheimer's and Huntington's diseases. Although the mechanism of dimebon action on pathological processes in degenerating brain is elusive, results of studies carried out in cell cultures and animal models suggested that this drug might affect the process of pathological accumulation and aggregation of various proteins involved in the pathogenesis of proteinopathies. However, the effect of this drug on the pathology caused by overexpression and aggregation of alpha-synuclein, including Parkinson's disease (PD), has not been assessed. Objective: To test if dimebon affected alpha-synuclein-induced pathology using a transgenic animal model. Methods: We studied the effects of chronic dimebon treatment on transgenic
\end{abstract}

mice expressing the C-terminally truncated (1-120) form of human alpha-synuclein in dopaminergic neurons, a mouse model that recapitulates several biochemical, histopathological and behavioral characteristics of the early stage of PD. Results: Dimebon did not improve balance and coordination of aging transgenic animals or increase the level of striatal dopamine, nor did it prevent accumulation of alphasynuclein in cell bodies of dopaminergic neurons. Conclusion: Our observations suggest that in the studied model of alpha-synucleinopathy dimebon has very limited effect on certain pathological alterations typical of PD and related diseases.

Copyright $\odot 2011$ S. Karger AG, Basel

\section{Introduction}

Dimebon is an over-the-counter drug that has been used as a non-selective oral antihistamine from 1983 and until more selective agents became available. In addition to its major activity as an inhibitor of histamine $\mathrm{H} 1$ and $\mathrm{H} 2$ receptors [1], dimebon has been reported to inhibit

\section{KARGER}

(C) 2011 S. Karger AG, Basel

Fax +4161306 1234

E-Mail karger@karger.ch

www.karger.com
Accessible online at:

www.karger.com/ndd
Natalia N. Ninkina

School of Biosciences, Cardiff University

Museum Avenue

Cardiff, CF10 3AX (UK)

Tel. +44292087 9068, E-Mail ninkinan@cf.ac.uk 
butyrylcholinesterase and acetylcholinesterase, voltagegated calcium channels, N-methyl-D-aspartatic acid, adrenergic receptors and serotonin receptors and mitochondrial permeability transition pore opening, as well as to stabilize glutamate-induced $\mathrm{Ca}^{2+}$ signals and enhance hippocampal neurogenesis [2-6]. Consequently, it has been suggested that dimebon may be used as a neuroprotective drug slowing down the progression of diseases characterized by gradual deprivation of cognitive functions.

Indeed, dimebon demonstrated cognition and memory-enhancing properties in rats treated with the neurotoxin AF64A, a compound that selectively destroys cholinergic neurons, and it protected cerebellar neurons in cell culture against beta-amyloid fragment-caused neurotoxicity [7]. In clinical trials dimebon improved cognition and memory of Alzheimer's disease [8] and Huntington's disease [9] patients. The pathogenesis of these two etiologically and clinically diverse neurodegenerative disorders shares a common feature, namely accumulation and deposition of aggregation-prone proteins (beta-amyloid and huntingtin, respectively) and therefore, they belong to a class of diseases known as proteinopathies [10], which also include Parkinson's disease (PD). A suggestion that dimebon may interfere with the process of protein aggregation and deposition instigated studies of the effect of this drug in various models of proteinopathies. It has been demonstrated that dimebon is capable of inhibiting the formation of TDP-43 inclusions in cellular models [11] and the formation/clearance of pathological deposits in a mouse model of gamma-synucleinopathy [12].

One of the most prominent features of PD is aggregation of alpha-synuclein with formation of toxic intermediates and characteristic cytoplasmic deposits of final aggregation products [13]. However, the effect of dimebon on alpha-synuclein aggregation in models of this neurodegenerative disorder or on disease progression in PD patients has not been assessed. The aim of the present study was to check whether dimebon is able to ameliorate the pathology caused by accumulation of alpha-synuclein in vivo.

Transgenic mice expressing mutated forms of human alpha-synuclein, which cause neuronal dysfunction through a toxic gain-of-function mechanism, are the most adequate model systems for such study. It is beyond doubt that successful neuroprotective therapies would be most effective when used at an early clinical or even preclinical stage of the disease when it is still possible to slow down or reverse its development. Thus, it seemed reasonable to assess the effect of dimebon in a mouse model replicating early stages of PD pathology. Mice expressing the truncated (lacking the C-terminal 20 amino acids) form of human alpha-synuclein under control of tyrosine hydroxylase $(\mathrm{TH})$ promoter on the endogenous alphasynuclein null background, further referred to as aSyn (1-120) TG, recapitulate features of early-stage PD. Adult mice show no marked loss of dopaminergic neurons and only minor defects in the nigrostriatal system [14]. The late-onset pathology includes rare human alpha-synuclein-positive neuronal inclusions, reduction in striatal dopamine content associated with decreased locomotion and progressive reduction of striatal dopamine release associated with SNARE protein redistribution and synaptic alpha-synuclein accumulation [15]. However, these animals do not develop severe motor deficit characteristic for advanced stages of PD [13]. Olfactory impairment is observed in $70-95 \%$ of patients with PD and precedes the severe motor symptoms by up to 4 years [16-18]. In aSyn (1-120) TG mice the highest levels of exogenous transgene expression and accumulation were detected in the olfactory bulb (OB) dopaminergic neurons [14]. The aSyn (1-120) TG mice represent a model mirroring the earliest alterations in the dopaminergic systems that precede significant neuronal loss in PD. Here, we use this model to study the effects of chronic dimebon treatment on biochemical and histological markers of pathology induced by expression of mutated human alpha-synuclein.

\section{Animals and Methods}

\section{Animals}

The transgenic mouse line aSyn (1-120) TG was created on the alpha-synuclein null background [18] as described previously [14, 15]. Only male mice were used in this study. Experimental mice were housed one per cage with a normal light/dark cycle and ad libitum access to food and water. All animal experiments were carried out in accordance with the UK Animals (Scientific Procedures) Act, 1986. The minimal required number of animals was used and all efforts were made to minimize animal suffering.

Dimebon Administration

Dimebon (3,6-dimethyl-9-(2-methyl-pyridyl-5)-ethyl-1,2,3,4tetrahydro- $\gamma$-carboline dihydrochloride) was obtained from OJSC Organika (Novokuznetsk, Russia). A cohort of aSyn (1-120) TG male mice received dimebon with the drinking water $(10 \mu \mathrm{g} /$ $\mathrm{ml}$ solution that was changed 3 times a week) from the age of 3 months. Control littermate animals received drinking water without dimebon. At the age of 14 months mice were behaviorally tested and tissues were collected for further analysis.

\section{Behavioral Tests}

Home-Like Cage Activity. Spontaneous locomotor activity was assessed in the home-like cage equipped with a system of infrared 
beams to monitor horizontal movements. Animals were monitored for $24 \mathrm{~h}$ with a normal light/dark cycle and ad libitum access to food and water. Exploratory activity in the novel environment was analyzed for $2 \mathrm{~h}$ after placing mice in the home-like cage for the first time. Data (number of beam breaks) were collected at $15-$ min intervals.

Rotarod Test. Animals were introduced to the rotarod (UGO Basil 7560, Italy) for $5 \mathrm{~min}$ and tested using an accelerating (from 4 to $40 \mathrm{rpm}$ over $300 \mathrm{~s}$ ) mode later on the same day. Each animal was tested 3 times with a 30 -min break between tests. The mean of latency to fall for these three trials was included in final statistics. Results were expressed as mean \pm SEM for each experimental group.

Inverted Grid Test. Balance and coordination were assessed as the ability of animals to stay on the inverted grid. Mice were placed on a $30 \times 30 \mathrm{~cm}$ square mesh consisting of $5-\mathrm{mm}$ squares of $0.5-\mathrm{mm}$ diameter wire. The grid was slowly rotated to inverted position and held $30 \mathrm{~cm}$ above the surface of a thick layer of bedding material. The latency to fall (in seconds) was noted. The maximum test time was $60 \mathrm{~s}$. The best time from three attempts was included in the statistics.

\section{Immunohistochemistry}

For the quantification of dopaminergic neurons in the substantia nigra pars compacta (SNpc) and ventral tegmental area, brains of control and experimental animals were simultaneously collected, processed, embedded and stained with antibody against TH as described previously $[20,21]$. Alexa Fluor-conjugated goat anti-rabbit and anti-mouse antibodies (Invitrogen) were used as secondary antibodies in double-immunofluorescence experiments.

\section{Neuronal Cell Counts}

Dopaminergic neurons in the SNpc and ventral tegmental area of experimental and control mice were stereologically counted using fractionator method and the Axiovision imaging program (Carl Zeiss Vision) as described in our previous publications $[20,21]$.

\section{Antibodies}

Mouse monoclonal antibody against TH (clone TH-2, Sigma) was used for staining of histological sections in 1:1,000 dilution. Mouse monoclonal antibody Syn-1 (Transduction Laboratories) was used in 1:1,500 dilution for detection of alpha-synuclein on immunoblots and in 1:100 dilution for double-immunofluorescence analysis together with rabbit polyclonal antibody against TH (H-196, Santa Cruz Biotechnology) diluted 1:100.

\section{High-Pressure Liquid Chromatography Analysis}

Monoamines were extracted by homogenization of dissected mouse dorsal striata in $0.06 \mathrm{M} \mathrm{HClO}_{4}$. Concentrations of striatal dopamine and 3,4-dihydroxyphenylacetic acid (DOPAC) were measured by high-pressure liquid chromatography (HPLC) with electrochemical detection using a $4.6 \times 150 \mathrm{~mm}$ Microsorb C18 reverse-phase column (Varian) and Decade II ECD with a Glassy carbon working electrode (Antec Leyden) set at $+0.7 \mathrm{~V}$ with respect to a $\mathrm{Ag} / \mathrm{AgCl}$ reference electrode. The mobile phase consisted of $12 \%$ methanol (v/v), $0.1 \mathrm{M}$ monosodium phosphate, 2.4 mM 1-octane sulphonic acid, 0.68 mM EDTA, pH 3.1.

\section{Immunoblotting}

Olfactory bulbs were dissected and homogenized directly in SDS-PAGE loading buffer followed by incubation for $10 \mathrm{~min}$ at $100^{\circ} \mathrm{C}$. Protein concentration was measured, and equal amounts of total protein were run on $14 \%$ SDS-PAGE and transferred to PVDF membrane using iBlot technology according to manufacturer's (Invitrogen) instructions. Membrane blocking, incubation with antibodies, washes and enhanced chemiluminescence detection were carried out as described previously [20,21].

RNA Expression Analysis

Total RNA extraction, first-strand cDNA synthesis and quantitative PCR on a StepOne Real-Time PCR System (Applied Biosystems) were performed as described previously [22]. Primers 5'-GAATCCTGGAAGACATGCCT-3' and 5'-AGGCTTCAGGCTCATAGTCT-3' were used for amplification of alpha-synuclein cDNA. For amplification of GAPDH mRNA (normalization standard) primers 5'-CACTGAGCATCTCCCTCACA-3' and 5'GTGGGTGCAGCGAACTTTAT-3' were used. Fold change was determined by $2^{-\Delta \Delta C T}$ method [23] using StepOne v2.0 software.

\section{Statistical Analysis}

All calculations were performed using STATISTICA 6.0 software. Non-parametric Kruskal-Wallis one-way ANOVA on ranks and Mann-Whitney $U$ test were used to assess differences between experimental groups.

\section{Results}

\section{Effect of Chronic Dimebon Treatment on Mouse Locomotion, Exploratory Activity, Balance and Coordination}

Analysis of dimebon-treated and control mice locomotion in a home-like cage during a 24 -hour period revealed no statistically significant difference $(\mathrm{p}=0.662)$ between the groups (fig. 1A). This indicates that chronic dimebon treatment does not affect spontaneous locomotor activity of aSyn (1-120) TG mice. However, dimebontreated transgenic mice were significantly $(\mathrm{p}=0.019)$ more active than control transgenic mice in a novel nonanxiogenic environment during the first $15 \mathrm{~min}$ of habituation, when their activity was similar to activity of wild-type mice (fig. 1B).

Balance and coordination of transgenic mice that did or did not receive dimebon and age-matched wild-type animals were assessed in inverted grid and accelerating rotarod tests (fig. 1C, D). No difference in the ability to stay on the inverted grid was observed between the three groups ( $p>0.05)$. Although 14-month-old aSyn (1-120) TG mice noticeably underperformed in the rotarod test compared to wild-type animals of the same age ( $\mathrm{p}=$ 0.030 ), chronic administration of dimebon did not improve their performance $(\mathrm{p}=0.806)$. 


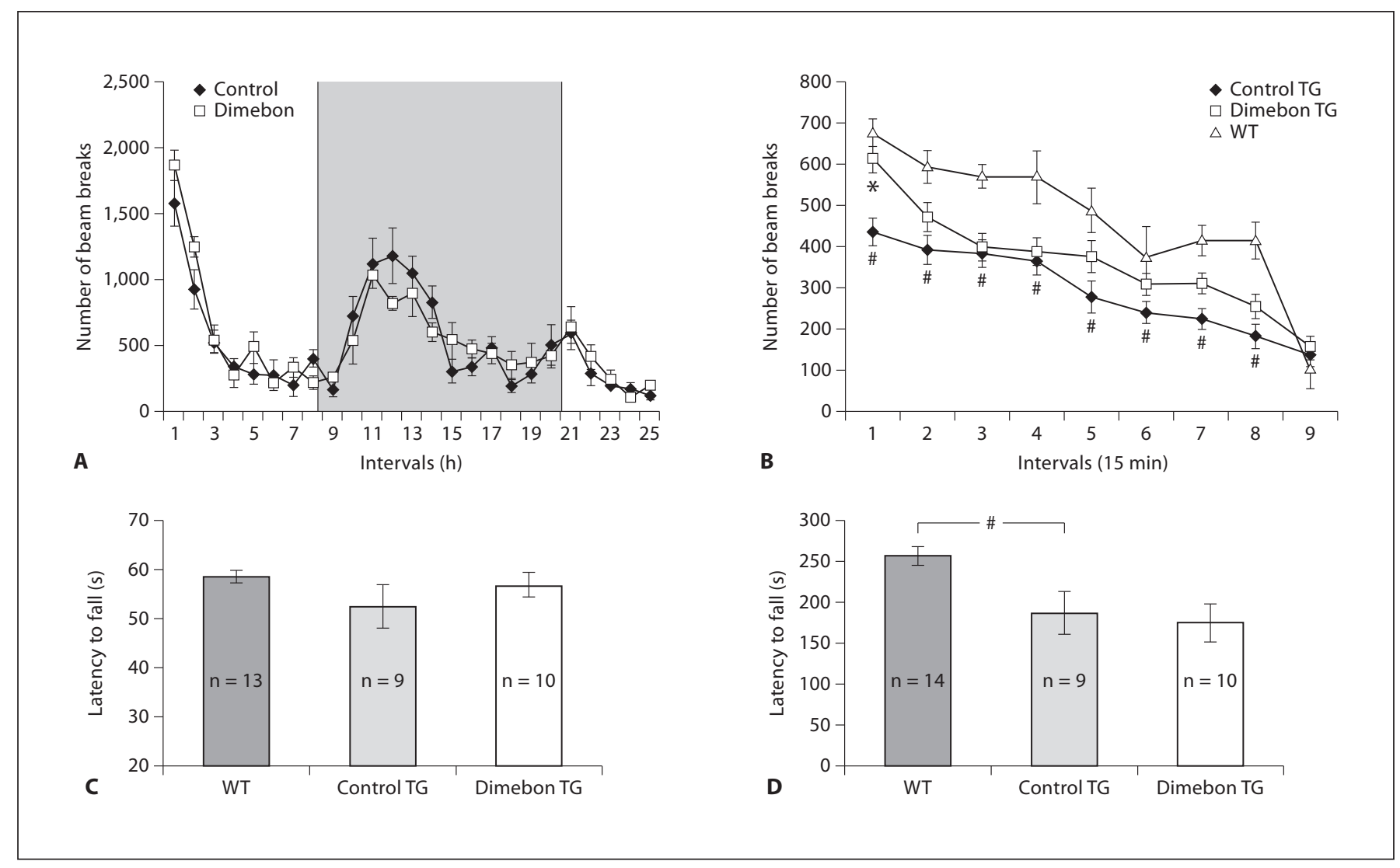

Fig. 1. Locomotor activity, balance and coordination of 14-monthold dimebon-treated and control mice. A Spontaneous locomotion of mice in the home-like cage measured as the number of beam breaks per 1-hour interval over a period of $24 \mathrm{~h}$. The dark phase of the light cycle is shaded. Graphs show results (means \pm SEM) for 8 dimebon-treated and 7 naïve aSyn (1-120) TG mice. Statistical analysis revealed no significant difference between two groups. B Locomotor activity of mice in novel non-anxiogenic environment recorded during the first $120 \mathrm{~min}$ in a home-like cage. Graphs show means \pm SEM of the number of beam breaks per 15-min interval for each group of animals. Statistically significant differences between activity of dimebon-treated and naïve aSyn $(1-120)$ TG mice $(* p<0.05)$ or naïve aSyn $(1-120)$ TG and wild-type $(\mathrm{WT})$ mice $\left({ }^{\#} \mathrm{p}<0.05\right)$ are shown. Bar charts show means \pm SEM of latency to fall from the inverted grid (C) or accelerating rotarod (D). aSyn (1-120) TG mice perform significantly worse ( $\left.{ }^{*} \mathrm{p}<0.05\right)$ than wild type mice in accelerating rotarod but not inverted grid test and dimebon does not affect their performance in both tests.

\section{Dopaminergic Neurons in the SNPc and Dopamine Content in the Dorsal Striatum of Dimebon-Treated Alpha-Synuclein Transgenic Animals}

It has previously been reported that expression of truncated human alpha-synuclein in dopaminergic neurons results in the development of pathological changes in the SNpc of aSyn (1-120) TG mice by the age of 12-14 months [14]. These changes include shrunken perikarya, beaded or dystrophic processes, inclusions and microgliosis, and may lead to progressive dysfunction of dopaminergic neurons. Therefore, we assessed effects of chronic dimebon administration on the number of dopaminergic neurons in the SNpc and dopamine content in the dorsal striatum of aSyn (1-120) TG mice. Stereological counting of TH-positive neurons showed that both dimebon-treated and non-treated transgenic mice have the same number of dopaminergic neurons in the SNpc (fig. 2A) as wild-type mice. This is consistent with the earlier observation that transgene expression does not cause detectable loss of TH-positive neurons in the SNpc of aSyn (1-120) TG mice [24] and demonstrates that dimebon has no effect on the survival of SNpc or ventral tegmental area (online supplementary fig. 1, see www.karger.com/doi/10.1159/000324989) dopaminergic neurons in adult animals. In contrast to unchanged number of neurons, the tissue content of dopamine and its 


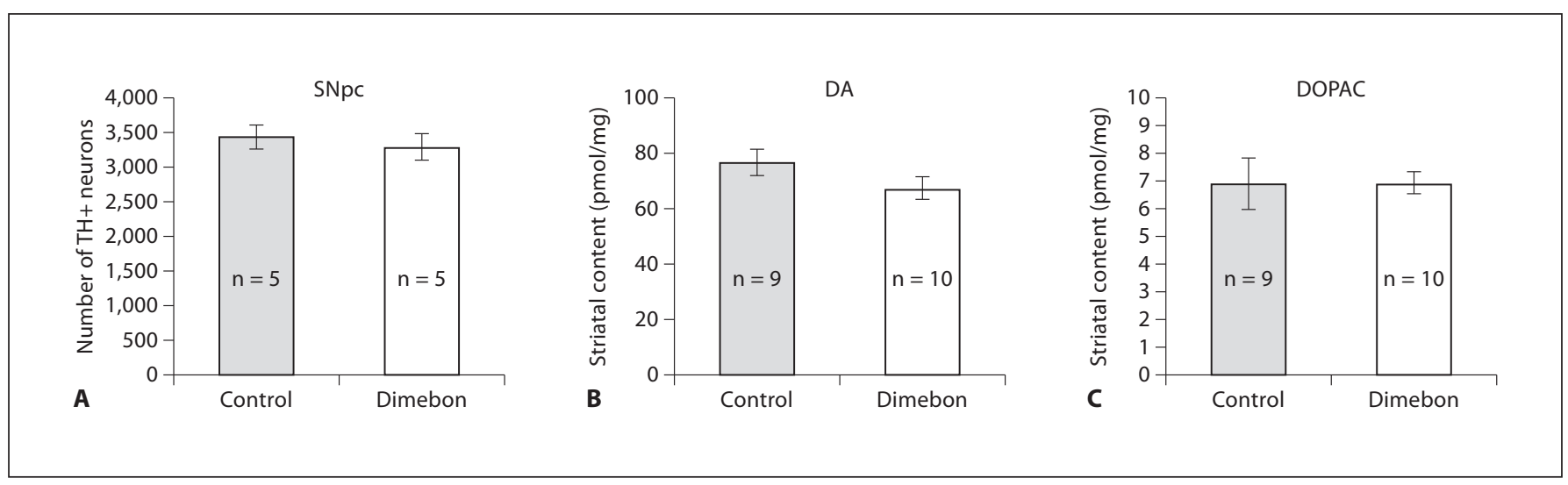

Fig. 2. The number of dopaminergic neurons in the substantia nigra and the content of monoamines in the dorsal striatum of 14-month-old dimebon-treated and control transgenic mice. A Bar chart shows means \pm SEM of total numbers of TH-positive neurons in the SNpc (per hemisphere) of dimebon-treated and control aSyn (1-120) TG mice. No statistically significant differ- ence between groups was found. Tissue content of dopamine (DA, B) and DOPAC (C) in the dorsal striatum of dimebon-treated and control aSyn (1-120) TG mice measured by HPLC with electrochemical detection and expressed as picomoles per milligram of tissue. Means \pm SEM are shown. Statistical analysis revealed no significant difference between the groups. metabolites is significantly reduced in the dorsal striatum of adult and aging aSyn (1-120) TG mice [14], which reflects the compromised function of the dopaminergic system in these mice [15]. Our HPLC analysis demonstrated the same dopamine and DOPAC content in the dorsal striatum of dimebon-treated and non-treated transgenic mice (fig. $2 \mathrm{~B}, \mathrm{C}$ ), suggesting that dimebon does not improve dopaminergic neuron function in this animal model.

\section{Dimebon Does Not Alter Transgene Expression, Accumulation or Intracellular Localization of Alpha-Synuclein in Dopaminergic Neurons of the Olfactory Bulb}

In aSyn (1-120) TG mice, the highest level of exogenous alpha-synuclein expression driven by the TH promoter was observed in the OB. To assess whether dimebon might influence the expression of transgene in neurons we studied the levels of human alpha-synuclein mRNA by quantitative RT-PCR and protein by immunoblotting in the $\mathrm{OB}$ of dimebon-treated and control aSyn (1-120) TG mice. For these experiments OBs of 6 dimebon-treated transgenic mice were combined in one group (D1) and OBs of another 4 similarly treated animals in another group (D2). Similarly, OBs of 4 and 5 non-treated transgenic mice were combined in groups $\mathrm{C} 1$ and C2. Total RNA and total proteins form each group of combined tissues were extracted and analyzed. The same level of human alpha-synuclein mRNA was detected in all four groups (fig. 3A). On immunoblots, the intensity of bands corresponding to the $12-\mathrm{kDa}$ truncated form of human alpha-synuclein protein was also very similar in four samples (fig. 3B). These results clearly demonstrate that dimebon does not affect transgene expression from the TH promoter or accumulation of exogenous alphasynuclein in dopaminergic neurons of the $\mathrm{OB}$.

In contrast to predominantly presynaptic compartmentalization of endogenous full-length alpha-synuclein and its exclusion from the perikaryon of dopaminergic neurons in the glomerular layer of $\mathrm{OB}$, ectopic accumulation of truncated human alpha-synuclein was observed in the cell bodies of these neurons (fig. 3C). However, simultaneous immunofluorescent staining of histological sections through the OB of dimebon-treated and control transgenic mice revealed no changes in either localization or the amount of alpha-synuclein accumulated in the cell bodies (fig. 3D).

\section{Discussion}

A disease-modifying effect of dimebon on the mild to moderate form of Alzheimer's disease and Huntington's disease has been demonstrated in phase II clinical trials [8]. Together with the recently shown ability of this drug to improve behavioral and histopathological impairments caused by pan-neuronal overexpression of gamma-synuclein $[12,22]$ these clinical data suggested that 


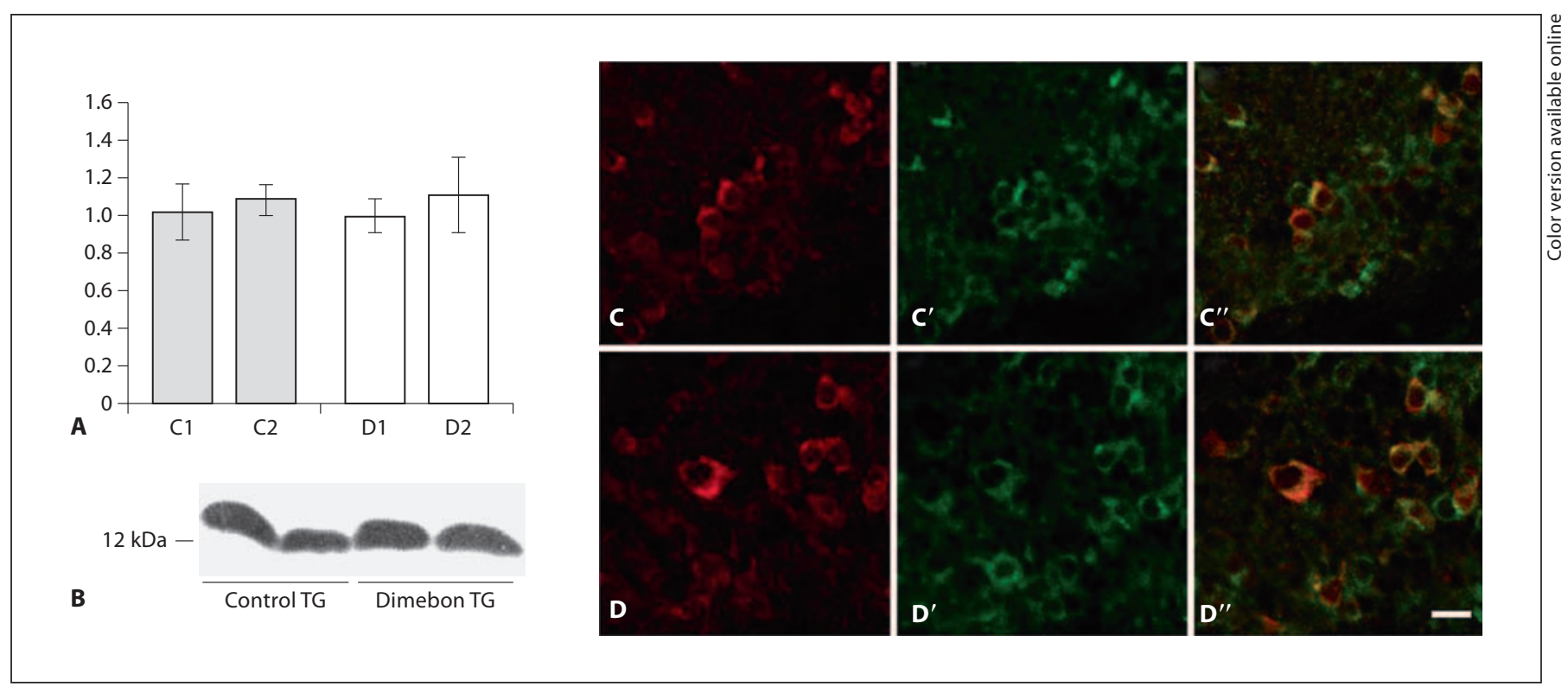

Fig. 3. Expression and accumulation of truncated human alphasynuclein in the $\mathrm{OB}$ of 14-month-old transgenic mice. A Quantitative RT-PCR analysis of human alpha-synuclein mRNA expression in the $\mathrm{OB}$ of dimebon-treated (D1 and D2) and control (C1 and C2) groups of aSyn (1-120) TG mice. The bar chart shows the fold of alpha-synuclein mRNA level (mean \pm SEM) normalised to the mean level in the D1 group. B Immunoblot detection of 12 $\mathrm{kDa}$ truncated human alpha-synuclein in protein samples extracted from $\mathrm{OBs}$ of the same animal groups as in $\mathbf{A}$. Total protein extracts (10 $\mu \mathrm{g}$ per lane) were separated by SDS-PAGE, transferred to PVDF membrane and probed with antibody against alpha-synuclein followed by enhanced chemiluminescence detection. C, D Immunofluorescent staining of histological sections through the glomerular layer of the $\mathrm{OB}$ of control (panels $\mathbf{C}-\mathbf{C}^{\prime \prime}$ ) and dimebon-treated (panels D-D') aSyn (1-120) TG mice with antibodies against TH (C, D) and alpha-synuclein $\left(\mathbf{C}^{\prime}, \mathbf{D}^{\prime}\right)$. Scale bar $=20 \mu \mathrm{m}$ for all panels. dimebon might be efficient in the treatment of various types of proteinopathies, including PD. Therefore, the main aim of this study was to evaluate the effects of dimebon in a mouse model recapitulating several characteristics of early-stage PD because results of clinical trials suggested that dimebon might protect against early rather than advanced forms of neurodegeneration. Experimental animals had constant access to drinking water containing $10 \mu \mathrm{g} / \mathrm{ml}$ of dimebon that was changed every $60 \mathrm{~h}$. Because of the stability of this compound in solutions [25-27] and the same rate of consumption for water and dimebon solution (average daily water consumption for mice in the control group was $5.2 \mathrm{ml}$ and average daily dimebon solution consumption for mice in the experimental group was $5.4 \mathrm{ml}$ ) this protocol permitted to achieve a cumulative daily dose of $\sim 54 \mu \mathrm{g} / 30-35 \mathrm{~g}$ mouse or $\sim 1.5 \mathrm{mg} / \mathrm{kg}$. This dose is close to the dose $(1 \mathrm{mg} / \mathrm{kg})$ used in the phase II clinical trials of dimebon for patients with Alzheimer's disease [8]. Moreover, recent studies have demonstrated that after oral administration of a single dose, dimebon levels in the plasma and in the brain of rodents are stable for at least $6 \mathrm{~h} \mathrm{[28]} \mathrm{and} \mathrm{therefore,} \mathrm{our}$ protocol of drug administration with drinking water supplied ad libitum assures uninterrupted exposure of the experimental animal brain to dimebon.

Mice of the aSyn (1-120) TG line expressing a truncated form of human alpha-synuclein in catecholaminergic neurons have previously been shown to develop an age-dependent reduction in exploratory activity in a novel environment [14]. Here we confirmed this effect on a separate cohort of 14-month-old aSyn (1-120) TG mice and over a longer period of adaptation to a novel environment $(120 \mathrm{~min}$ in contrast to $30 \mathrm{~min}$ in the previous study), and furthermore revealed that performance of these transgenic mice in the accelerated rotarod test is also markedly compromised when compared to the performance of age-matched wild-type animals. However, aging aSyn (1-120) TG mice performed very similarly to wild-type animals in the inverted grid test, suggesting that expression of the truncated form of human alphasynuclein in dopaminergic neurons causes very selective changes of animal behavior. In PD patients more than 
$80 \%$ reduction of striatal dopamine is required for the development of motor symptoms, whereas aSyn (1-120) TG mice display only $\sim 30 \%$ reduction [14], suggesting that their compromised rotarod performance could not be explained simply by dopamine deficiency but probably involves other functional changes in dopaminergic neurons or their synapses caused by expression of truncated human alpha-synuclein [15]. Thus, two behavioral parameters that appeared to be compromised in aSyn (1120) TG mice could be used for assessing the effect of dimebon on alpha-synuclein-induced pathology.

Transgenic mice chronically treated with dimebon for 11 months from the age of 3 months showed no improvement in the accelerated rotarod test compared to untreated animals of the same genotype. This correlated with the lack of the effect of dimebon on decreased levels of dopamine and DOPAC in the striatum of aSyn (1-120) TG mice.

The general activity of aging aSyn (1-120) TG mice in the home-like cage over a 24 -hour period was not affected by dimebon. However, immediately after placing in a novel environment, dimebon-treated animals were significantly more active than untreated transgenic animals, suggesting that dimebon intensifies exploratory activity, which is attenuated in 14-month-old aSyn (1-120) TG mice. As exploratory behavior depends on the coordinated function of many brain networks rather than solely the dopaminergic system, this effect might reflect a general improvement of aging brain function by dimebon as suggested in previous studies $[6-8,29]$.

Another prominent feature of the aSyn (1-120) TG model is the ectopic accumulation of transgenically expressed truncated human alpha-synuclein in cell bodies of dopaminergic neurons. This was most obvious in neu- rons of the glomerular layer of $\mathrm{OB}$ and therefore these cells seemed an appropriate system for assessing the effect of dimebon treatment on alpha-synuclein accumulation and intraneuronal localization. However, neither expression analysis nor the comparison of histological sections through the $\mathrm{OB}$ revealed differences in the tissue level or in the pattern of human alpha-synuclein immunostaining in TH-positive neurons of dimebon-treated and untreated aSyn (1-120) TG mice. We also did not observe any effect of dimebon on micro- or astrogliosis in the $\mathrm{OB}$ or other neural tissues of these mice.

In conclusion, we demonstrated a very limited effect of chronic dimebon treatment on the biochemical, histological and behavioral alterations caused by expression of truncated human alpha-synuclein in dopaminergic neurons of transgenic mice. Although these negative results question the value of dimebon as a potential treatment for $\mathrm{PD}$ and other alpha-synucleinopathies, it should be noted that aSyn (1-120) TG mice recapitulate only some changes typical of the early stages of these diseases and it is possible that this drug might affect other manifestations, for example, those associated with late disease stages. Further studies are required to reveal whether dopaminergic neurons are less sensitive to this drug than other previously studied types of neurons or whether dimebon does not affect pathways associated with alpha-synuclein toxicity in any other types of cells and at any stage of pathology.

\section{Acknowledgements}

This work was supported by Research Grants from the Russian Foundation for Basic Research, RAS 'Fundamental Science for Medicine', Alzheimer's Society and The Wellcome Trust (075615/Z/04/z).

\section{References}

1 Matveeva IA: Action of dimebon on histamine receptors. Farmakol Toksikol 1983;46: 27-29.

-2 Lermontova NN, Redkozubov AE, Shevtsova EF, Serkova TP, Kireeva EG, Bachurin SO: Dimebon and tacrine inhibit neurotoxic action of beta-amyloid in culture and block Ltype $\mathrm{Ca}(2+)$ channels. Bull Exp Biol Med 2001;132:1079-1083.

3 Grigorev VV, Dranyi OA, Bachurin SO: Comparative study of action mechanisms of dimebon and memantine on AMPA- and NMDA-subtypes glutamate receptors in rat cerebral neurons. Bull Exp Biol Med 2003; 136:474-477.
$4 \mathrm{Wu}$ J, Li Q, Bezprozvanny I: Evaluation of Dimebon in cellular model of Huntington's disease. Mol Neurodegener 2008;3:15.

5 Bachurin SO, Shevtsova EP, Kireeva EG, Oxenkrug GF, Sablin SO: Mitochondria as a target for neurotoxins and neuroprotective agents. Ann NY Acad Sci 2003;993:334-344.

6 Pieper AA, Xie S, Capota E, Estill SJ, Zhong J, Long JM, et al: Discovery of a proneurogenic, neuroprotective chemical. Cell 2010; 142:39-51

7 Bachurin S, Bukatina E, Lermontova N, Tkachenko S, Afanasiev A, Grigoriev V, et al: Antihistamine agent Dimebon as a novel neuroprotector and a cognition enhancer. Ann NY Acad Sci 2001;939:425-435.
8 Doody S, Gavrilova SI, Sano M, Thomas RG, Aisen PS, Bachurin SO, et al: Effect of dimebon on cognition, activities of daily living, behaviour, and global function in patients with mild-to-moderate Alzheimer's disease: a randomised, double-blind, placebo-controlled study. Lancet 2008;372:207-215.

-9 Kieburtz K, McDermott MP, Voss TS, CoreyBloom J, Deuel LM, Dorsey ER, et al; Huntington Disease Study Group DIMOND Investigators: A randomized, placebo-controlled trial of latrepirdine in Huntington disease. Arch Neurol 2010;67:154-160. 
-10 Skovronsky DM, Lee VM, Trojanowski JQ: Neurodegenerative diseases: new concepts of pathogenesis and their therapeutic implications. Annu Rev Pathol 2006;1:151-170.

- 11 Yamashita M, Nonaka T, Arai T, Kametani F, Buchman VL, Ninkina N, et al: Methylene blue and dimebon inhibit aggregation of TDP-43 in cellular models. FEBS Lett 2009; 583:2419-2424.

12 Bahurin SO, Ustyugov AA, Peters O, Shelkovnikova TA, Buchman VL, Ninkina NN: Hindering of proteinopathy-induced neurodegeneration as a new mechanism of action for neuroprotectors and cognition enhancing compounds. Dokl Biochem Biophys 2009;428:262-265.

-13 Spillantini MG, Schmidt ML, Lee VM, Trojanowski JQ, Jakes R, et al: Alpha-synuclein in Lewy bodies. Nature 1997;388:839-840.

- 14 Tofaris GK, Garcia-Reitböck P, Humby T, Lambourne SL, O’Connell M, Ghetti B, et al: Pathological changes in dopaminergic nerve cells of the substantia nigra and olfactory bulb in mice transgenic for truncated human alpha-synuclein(1-120): implications for Lewy body disorders. J Neurosci 2006;26: 3942-3950.

15 Garcia-Reitböck P, Anichtchik O, Bellucci A, Iovino M, Ballini C, Fineberg E, et al: SNARE protein redistribution and synaptic failure in a mouse model of Parkinson's disease. Brain 2010;133:2032-2044.

16 Doty RL, Stern MB, Pfeiffer C, Gollomp SM, Hurtig HI: Bilateral olfactory dysfunction in early stage treated and untreated idiopathic Parkinson's disease. J Neurol Neurosurg Psychiatry 1992;55:138-142.
17 Ward CD, Hess WA, Calne DB: Olfactory impairment in Parkinson's disease. Neurology 1983;33:943-946.

18 Katzenschlager R, Lees AJ: Olfaction and Parkinson's syndromes: its role in differential diagnosis. Curr Opin Neurol 2004;17: 417-423.

19 Specht CG, Schoepfer R: Deletion of the alpha-synuclein locus in a subpopulation of C57BL/6J inbred mice. BMC Neurosci 2001; 2:11-19.

20 Robertson DC, Schmidt O, Ninkina N, Jones PA, Sharkey J, Buchman VL: Developmental loss and resistance to MPTP toxicity of dopaminergic neurones in substantia nigra pars compacta of gamma-synuclein, alphasynuclein and double alpha/gamma-synuclein null mutant mice. J Neurochem 2004; 89:1126-1136.

21 Al-Wandi A, Ninkina NN, Millership S, Williamson SJM, Jones PA, Buchman VL: Absence of $\alpha$-synuclein affects dopamine metabolism and synaptic markers in the striatum of aging mice. Neurobiol Aging 2010;31: 796-804.

22 Ninkina N, Peters O, Millership S, Salem H, van der Putten H, Buchman VL: $\gamma$-Synucleinopathy: neurodegeneration associated with overexpression of the mouse protein Hum Mol Genet 2009;18:1779-1794.

23 Livak KJ, Schmittgen TD: Analysis of relative gene expression data using real-time quantitative PCR and the 2(-Delta Delta C(T)) method. Methods 2001;25:402-408.
24 Michell AW, Tofaris GK, Gossage H, Tyers P, Spillantini MG, Barker RA: The effect of truncated human alpha-synuclein(1-120) on dopaminergic cells in a transgenic mouse model of Parkinson's disease. Cell Transplant 2007;16:461-474.

25 Zefirov NS, Afanas'ev AZ, Afanas'eva SV, Bachurin SO, Bukatina EE, Grigor'eva IV, et al: Agent for treating neurodegenerative disorders. US Patent 6,187,785 B1; Applicant/ Assignee: Selena Pharmaceuticals Inc, CA. Issued Date: February 13, 2001.

-26 Nirogi R, Kandikere V, Mudigonda K, Komarneni P, Boggavarapu R: Liquid chromatography-tandem mass spectrometry method for the quantification of dimebon in rat plasma and brain tissue. J Chromatogr B Analyt Technol Biomed Life Sci 2009;877:35633571 .

27 Steele JW, Kim SH, Cirrito JR, Verges DK, Restivo JL, Westaway D, et al: Acute dosing of latrepirdine (Dimebon ${ }^{\mathrm{TM}}$ ), a possible Alzheimer therapeutic, elevates extracellular amyloid- $\beta$ levels in vitro and in vivo. Mol Neurodegener 2009;4:51.

28 Giorgetti M, Gibbons JA, Bernales S, Alfaro IE, Drieu La Rochelle C, Cremers T, et al: Cognition-enhancing properties of Dimebon in a rat novel object recognition task are unlikely to be associated with acetylcholinesterase inhibition or N-methyl-D-aspartate receptor antagonism. J Pharmacol Exp Ther 2010;333:748-757.

29 Zhang S, Hedskog L, Petersen CA, Winblad B, Ankarcrona A: Dimebon (latrepirdine) enhances mitochondrial function and protects neuronal cells from death. J Alzheimers Dis 2010;21:389-402. 